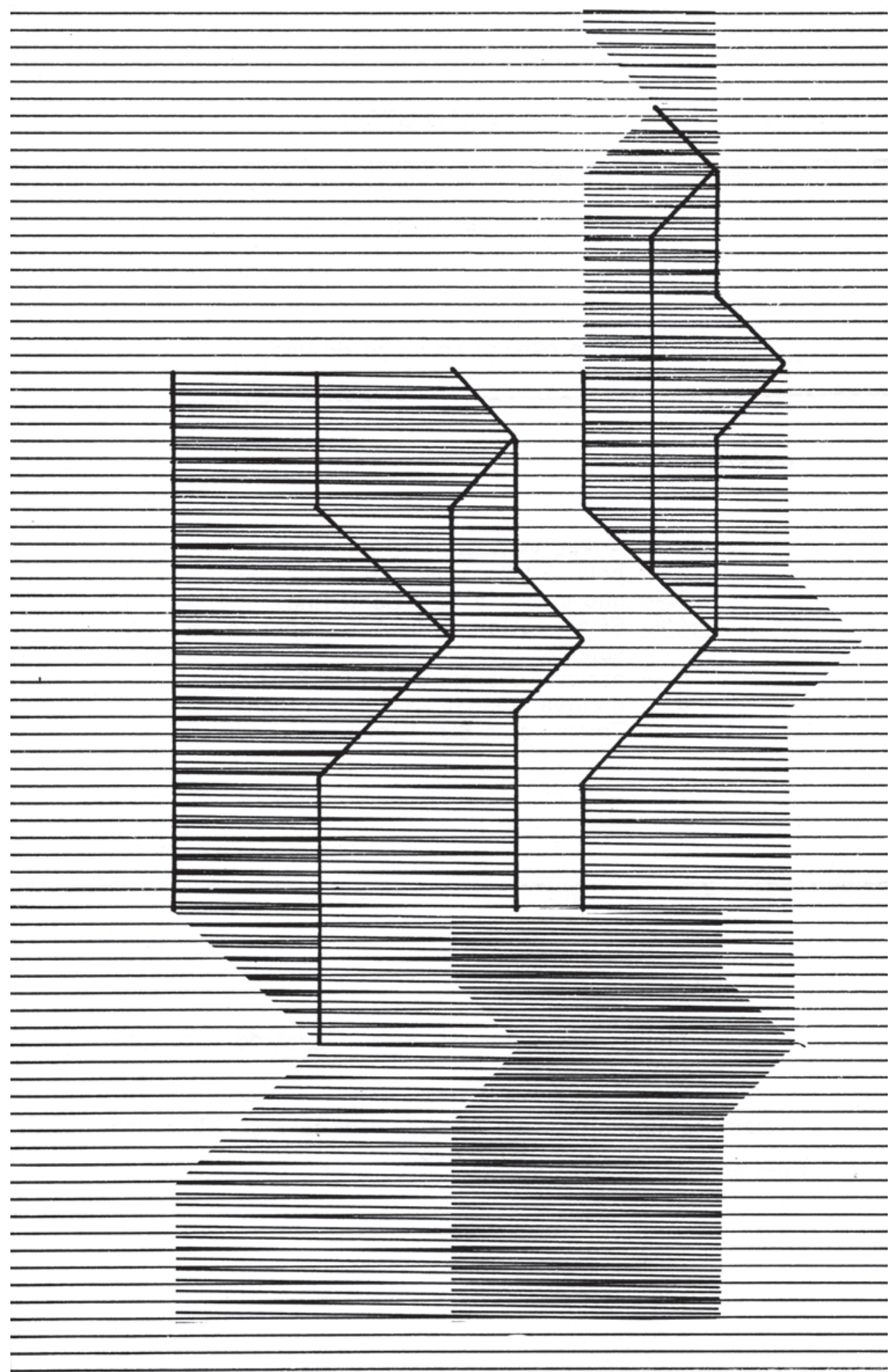


ARS Susana Piteira e Leonardo Charréu*

ano 13

n. 26 Campos expandidos da escultura na recuperação paisagística e urbana: um exemplo de arte pública e práticas colaborativas

\section{Expanded fields of sculpture in landscape and urban rehabilitation: an example of public art and collaborative practices}

palavras-chave: escultura; regeneração urbana/ rural; paisagem; práticas colaborativas

keywords: sculpture; urban/rural regeneration; landscape; collaborative practices

* Susana Piteira - doutoranda na Faculdade de Belas Artes de Barcelona e professora auxiliar convidada na

Faculdade de Belas Artes da Universidade do Porto Leonardo Charréu investigador colaborador no I2ADS (Instituto de investigação em Arte, Design Sociedades) da Universidade do Porto e do GEAPEC (Grupo de Estudos em Arte, Educação e Cultura) da Universidade Federal de Santa Maria.
Pretendemos discutir a inserção da escultura como elemento qualitativo na recuperação urbana e paisagística, a partir de um projeto de recuperação e reabilitação de um velho caminho rural, desenvolvido e implementado em Belver, pequena povoação rural do centro de Portugal. Destacamos o impacto e o debate conceitual gerados pelo projeto - financiado com fundos Europeus - sobre quem nele participou, assim como as práticas colaborativas entre políticos, arquitetos e artistas que consideramos serem relativamente raras em contextos similares. Elas permearam os princípios e processos em que o trabalho foi realizado, e por isso nos pareceram dignas de estudo e atenção.

We seek to discuss the sculpture insertion as qualitative element in urban and landscape rehabilitation project of an old country road, developed and implemented in Belver, a small rural town in central Portugal. We highlight the impact and the conceptual debate that was generated by the project - supported with EU funds - over who participated in it, as well as collaborative practices between politicians, architects and artists (sculptors) we consider to be relatively rare in similar contexts. They permeated the principles and processes in which the work was performed, and therefore they seemed worthy of study and attention. 


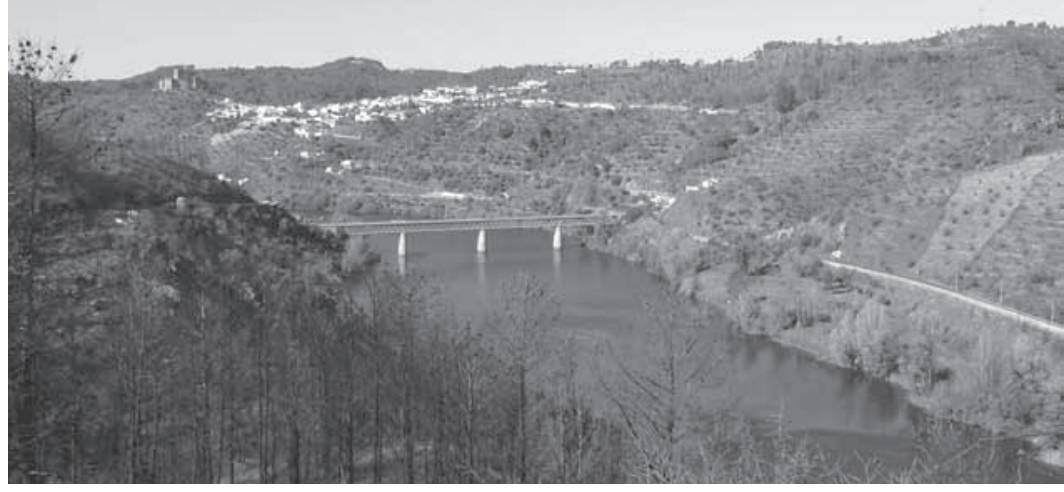

I'm more interested in the terrain dictating the condition of the art. Robert Smithson, "Fragments of a conversation"

\section{Introdução}

Belver é uma pequena vila ${ }^{1}$ que integra administrativamente o Munícipio do Gavião, na região do Alto Alentejo. Até há pouco mais de duas décadas, ela organizava-se essencialmente em torno da agricultura e da pastorícia. No presente, como consequência da profunda alteração socioeconômica que vivemos, Belver sofre os mesmos constrangimentos de toda a área rural de Portugal e de outros países com semelhantes processos de adaptação às formas e ritmos do mundo contemporâneo.

Perdendo gradualmente sua estrutura própria, assentada na agricultura, na pastorícia e, por conseguinte, nas valências associadas a esse tipo de economia, por vezes de subsistência, assistimos ao abandono gradual e à degradação, pelo menos física, destes lugares. Como exemplo, podemos citar a problemática recente dos incêndios florestais, acentuada em muitos casos pela profunda e crescente desertificação territorial, quer pelo abandono do uso dos campos, quer pela ausência da vigilância própria de quem ainda "habita" os lugares (nas férias) mas não vive ali permanentemente. Assistimos por isso ao abandono de partes significativas do território português em detrimento da fixação maciça da população na orla costeira atlântica.

Mas, perdida a vocação de um lugar, o que fazer? Abandoná-lo totalmente a seu destino solitário! Ou inventar uma outra vocação que dê sentido a esse sítio, de modo a que possa vir a tornar-se um novo/ outro lugar?!

\section{Susana Piteira}

Leonardo Charréu

Campos expandidos da escultura na recuperação paisagística e urbana: um exemplo de arte pública e práticas colaborativas

Figura 1:

Vista panorâmica da vila de Belver, com o rio Tejo em primeiro plano (Créditos Fotográficos: Mário Reis/ Susana Piteiral

1. Em Portugal, utiliza-se os termos "aldeia", "vila e "cidade" para designar as povoações em termos de expansão e número de habitantes. Assim, uma vila será um pouco maior que uma aldeia e menor que uma cidade. Na escala demográfica portuguesa, naturalmente bem diferente, por defeito, da brasileira, uma vila poderá ter entre (pouco mais de) mil e quinze mil habitantes dependendo da densidade demográfica da região onde está implatada. 

Gavião optou claramente por rentabilizar os recursos naturais, paisagísticos e patrimoniais do seu concelho, que se situam sobretudo em Belver, apetrechando-o com um diversificado conjunto de equipamentos e de ações com finalidades de lazer e turismo. Esses equipamentos - tão diversos como uma praia fluvial, um hotel com atividades desportivas - e ações - como a reestruturação do largo da igreja e a intervenção de restauro do Caminho da Fonte Velha: um antiquíssimo caminho medieval que ligaria o centro da vila a uma das suas periferias rurais - foram suportadas, em parte, por projetos comunitários. Contaram com assessores técnicos e mediadores capazes de dar resposta a suas solicitações, através de concursos públicos. Daqui advém, como enunciaremos mais à frente, o início de uma forte intencionalidade e disposição programá-

Figura 2: Vista panorâmica de Belver, com o castelo medieval em segundo plano (Créditos Fotográficos: Mário Reis/ Susana Piteiral tica por parte de quem tem o poder de decidir: os políticos (autarcas locais), logo seguidos pelos arquitetos e... pelos artistas (escultores).

$\mathrm{O}$ início do século XXI viu então surgir, um pouco por todo o país, um importante número de programas denominados de reabilitação arquitetônica ou urbana, impulsionados por significativas verbas oriundas da União Europeia. Este período de bonança para as políticas públicas, das quais este projeto é também resultado, assumiu contornos de fenômeno contemporâneo e, de certa forma, de (re)ordenação do território português, pois o programa foi largamente aplicado em fragmentos de norte a sul do país. Não é de estranhar que tivesse deixado saudades entre os agentes culturais que viram nele uma oportunidade irrepetível de melhor qualificar os ambientes urbanos e rurais.

Através da apresentação de um caso peculiar de reabilitação de um ancestral caminho rural, o Caminho da Fonte Velha, possibilitado pelo Programa Polis, tentaremos abordar esse tema e algumas das implicações mais diretas relacionadas com as suas três grandes dimensões processuais, a saber: a forte determinação e vontade político-estética de um programa de regeneração urbana e de arte pública, a interdisciplinaridade entre os vários campos e as práticas colaborativas entre os vários atores em ação.

O programa Polis criado em 2000 pelo então governo socialista (pelo seu ministro do ambiente), aparecia como "uma ambiciosa política de qualificação ambiental e urbanística das cidades portuguesas”. Desta forma, ambicionava-se encontrar meios que permitissem "realizar transformações qualificantes, de grande visibilidade e impacto, nas nossas 
principais urbes”2 . Este programa de requalificação, associado a um forte planejamento e compromisso político (local) e a uma igual determinação dos vários elementos da equipe que aplicou o projeto (políticos autarcas, escultores, trabalhadores da empresa contratada etc.), liderada pela ação mediadora de seus arquitetos, proporcionou uma base de trabalho invulgar cujo produto foi o resultado do desenvolvimento desse processo interdisciplinar e colaborativo do qual este texto procura dar conta.

A intervenção de arquitetura e restauro do Caminho da Fonte Velha, pelas suas peculiares características, permite-nos avaliar de que forma os microprojetos de arquitetura e de urbanismo podem contribuir para o reordenamento do território e como, também, podem alterar o caráter dos lugares. Avaliamos também aqui o papel da arte na reformulação do espaço, nomeadamente sua responsabilidade na criação de um espaço público com mais qualidade, atentando para como a intervenção de elementos escultóricos e o ensaio do conceito de instalação, ou de espaço raptado à arquitetura ${ }^{3}$, foram determinantes como linha mestra do programa.

Segundo Francoise Choay, o urbano não é sinônimo de urbanidade nem mesmo propriedade exclusiva da cidade. Podemos imaginar núcleos de urbanidade de tamanhos e formas múltiplas que podem ser projetados para espaços aparentemente rurais se tomados sua localização geográfica e suas características gerais. Esses núcleos podem entrar em uma dialética com o urbano propriamente dito, igual à que antigamente vinculava a cidade e o campo como entidades geográficas específicas e bem delimitadas ${ }^{4}$.

Já Bruno Soares ${ }^{5}$ vê na qualificação das periferias urbanas, mas também dos espaços rurais, uma forma de combater os efeitos negativos da dispersão e do desordenamento quase caótico que hoje vemos vulgarizar-se em qualquer subúrbio urbano. A ideia é exatamente a de, ao planejar e qualificar essas periferias, conseguir uma entidade territorial específica bem diferenciada da cidade tradicional. No fundo, trata-se de um espaço que nem é cidade nem é campo, mas possui as características de um e de outro, para usufruto qualitativo dos seus habitantes.

Nesse contexto, as perspectivas de Françoise Choay e de Bruno Soares, parecem-nos afirmar a necessidade contemporânea de tratar o território a duas escalas distintas e simultâneas: a escala da totalidade do território - ou macro, se quisermos - articulando uma outra escala, a das entidades territoriais específicas, a dos fragmentos de território que, em conjunto, compõem a escala macro.

Não vamos nos deter detalhadamente nas questões que per-
Susana Piteira

Leonardo Charréu

Campos expandidos da escultura na recuperação paisagística e urbana: um exemplo de arte pública e práticas colaborativas

2. FERREIRA, António F. Gestão estratégica de cidades e regiões. Lisboa: Fundação Calouste Gulbenkian, 2005, p. 184

3. Cf. MADERUELO, Javier. El espacio raptado. Interferencias entre Arquitectura y Escultura. Madrid: Mondadori, 1990.

4. Cf. CHOAY, Françoise. El Reino de lo Urbano y la Muerte de la Ciudad. In UNIVERSITAT POLITECNICA DE CATALUNYA, Lo urbano en 20 autores contemporáneos. Barcelona: Edicións UPC, 2004.

5. Cf. SOARES, Bruno. A realidade incontornável da dispersão. In: FERREIRA, A. F. Gestão estratégica de cidades e regiões. Lisboa: Fundação Calouste Gulbenkian, 2005. 


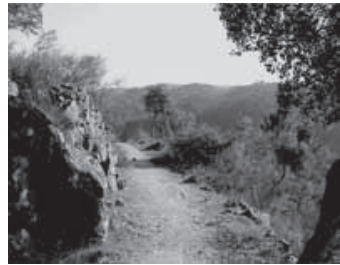

Figura 3 e 4: 0 "antes" e o "depois" da recuperação do Caminho da Fonte Velha. Detalhe, a escultura de chão, cabeça antropomórfica de Victor Ribeiro (Créditos Fotográficos: Mário Reis/ Susana Piteiral.

6. FERREIRA, António F. Op. cit., p. 184

7. 0 que consideramos destualizado é o conceito de "plano de pormenor", embora se encontre legalmente em vigor em Portugal, com toda uma série exigências que por vezes dificultam a consumação dos projetos. tencem à história recente do urbanismo em Portugal. Gostaríamos sobretudo de salientar que o projeto de reabilitação do Caminho da Fonte Velha foi, como já sublinhamos, lançado através do programa Polis e, portanto, dependente da figura do "plano de pormenor" ${ }^{\text {, }}$ o que poderia ter causado, como em muitos outros casos conhecidos, algum obstáculo ao seu desenvolvimento. Contudo, por razões que abordaremos a seguir, a reordenação deste fragmento de nosso território, embora ancorado em uma estrutura jurídica desatualizada ${ }^{7}$, acabou por concretizar-se e assumir-se no âmbito das "entidades territoriais específicas" consumando assim uma prática de vanguarda e contribuindo, a partir de uma escala micro, para o reordenamento global do território.

No âmbito do trabalho interdisciplinar, sendo conhecida a grande desarticulação em Portugal (e quiçá em outros países também) entre as diversas disciplinas que são chamadas a configurar o território e, de forma mais específica, o espaço público, pareceu-nos extremamente pertinente abordar o caso da intervenção no Caminho da Fonte Velha, projetado em 2000 e executado entre 2001 e 2004. Este caso peculiar (em Portugal) de reabilitação de um espaço ancestralmente rural obrigou que fosse realizado um interessante ensaio processual de avaliação da qualidade do programa Polis e da transversalidade entre disciplinas (de uma forma direta, a arquitetura, a escultura e a política, de uma forma mais indireta, a antropologia, a sociologia, e a etnografia...), pouco usual em termos da prática dos atores nacionais normalmente encarregados de projetar a recuperação e reabilitação do território.

Apreciando o processo do projeto do Caminho da Fonte Velha 
162

verificamos que o programa Polis é aqui aplicado de forma sui generis, contrariando em parte seus próprios objetivos. A saber: o espaço de intervenção não é o centro histórico (como na esmagadora maioria dos projetos contemporâneos), mas um percurso que dele sai e a ele retorna: "ir à fonte e voltar, fez, faz e continuará a fazer parte de um quotidiano que, mesmo em tempo de mudança, continua misterioso, por vezes necessário”. Um percurso misto, que se desenvolve em parte dentro da área do perímetro urbano da vila e, em parte, numa área fora desse mesmo perímetro ${ }^{9}$. Entra aqui, portanto, uma sensibilidade, por parte dos projetistas, que é tanto etnográfica quanto antropológica, apesar de não se encontrar nenhum etnógrafo ou antropólogo entre a equipe. Procurou-se recuperar uma prática de percurso pedestre local que se tinha perdido com a ruína da fonte velha. Enfim, voltar a fazer circular pessoas da pequena cidade, entre seu miolo e casco histórico e sua periferia mais campestre. No fundo, induzir de novo a circulações de pessoas num trajeto cheio de história, que o tempo e as condições socioeconômicas tinham esbatido ou apagado.

A equipe de arquitetos, ao concorrer com um projeto de reabilitação, contraria a própria lógica do concurso pois apresenta uma solução em que o mote fundamental é "renaturalizar o lugar", introduzindo no caminho "qualquer coisa que fosse suficientemente apelativa para que a população o continuasse a usar com afetividade" ${ }^{10}$. A Câmara Municipal do Gavião aceitou o desafio apoiando-se na reconhecida qualidade de trabalho do ateliê Victor Mestre / Sofia Aleixo, Arq. Lda., com quem já tinha desenvolvido outros projetos no Município de Gavião, manifestando assim a determinação e vontade política fundamental à afirmação da diferença que o projeto viria a assumir.

Tomou-se portanto o projeto como algo mais que o tradicional desenho. Ou, se quisermos, o desenho teve a capacidade de atuar em três níveis, como sugere Antoni Remesar ${ }^{11}$, nos quais se articulou a intervenção no espaço: o plano, o projeto e a peça. Políticos, arquitetos, artistas, assim como também, de certo modo, os executores (trabalhadores da empresa contratada para levar a cabo os trabalhos de engenharia civil) confrontaram-se, criando novas estratégias, atitudes, negociações de pontos de vista e posicionamentos, assim como obrigando a conhecerem as respectivas limitações e/ou as oportunidades dos respectivos campos de intervenção.

O peculiar castelo, com escala adequada ao lugar, impõe-se em
Susana Piteira

Leonardo Charréu

Campos expandidos da escultura na recuperação paisagística e urbana: um exemplo de arte pública e práticas colaborativas

8. MESTRE, Victor; ALEIXO, Sofia; PÉ-CURTO, Jorge. Recuperação do Caminho da Fonte Velha. Câmara Municipal de Gavião: Belver. Memória Descritiva, Relatório não publicado, 2000, p. 2.

9. Considerada tradicionalmente como rural.

10. MESTRE, Victor. Pesquisa de doutorado Arte, natureza e cidade em Portugal: uma tentativa de programação de arte pública. Lisboa, 1 jul. 2004. Entrevista concedida à Susana Piteira, p. 3.

11. Ver REMESAR, Antoni (ed.). Urbanscapes of glocalization. Barcelona: CER Polis. Universitat de Barcelona, 2000. 
relação à vila, sobranceiro ao rio Tejo, assumindo-se quase como uma escultura de vulto perfeito. Contrapondo o castelo (fig. 2), o caminho da fonte (fig. 5) desenvolve-se ao logo da encosta, de um forma mais discreta, por vezes imperceptível, camuflado pela vegetação que o acompanha (fig. 3 e 4). Poderíamos afirmar, se falássemos apenas a partir do âmbito da teoria da escultura, que o castelo poderia ser um monumento, participando na vida diária da população desta vila apenas como objeto visual e, o caminho da fonte, uma instalação participada pelas funções exercidas ao longo do seu percurso, durante séculos. Dessa forma, afirma-se o forte caráter deste lugar e reivindica-se a tensão entre objeto (o castelo) e espaço (o caminho da fonte) que polariza a paisagem e determina a sua interessantíssima dimensão cênica.

O projeto de arquitetura foi desenvolvido a partir de duas premissas: a conservação e a intervenção escultórica. A primeira implicou que para conservar era preciso intervir e foi neste paradoxo que residiu o projeto $^{12}$. A segunda, decorre desta última e associou-se à vontade de deixar uma marca dessa recuperação. De acordo com o escultor Jorge Pé-Curto, convidado a coordenar o projeto de intervenção escultórica:

Ao preservar a "memória de um lugar", como se pretende com a recuperação do Caminho Rural da Fonte Velha, seria errado não deixar uma marca da época dessa recuperação. É esta a principal razão desta intervenção escultórica, que ao evocar o mundo das formas envolventes, proporciona ao visitante um clima emocional que enriqueça a sua compreensão ${ }^{13}$.

Dessa forma, a escultura, ao tornar-se uma marca da intervenção, assumiu-se como o tema do projeto, pretendendo assinalar o percurso com uma pista de símbolos, implantados sutilmente ao logo do caminho ${ }^{14}$.

Paralelamente, outras pequenas alterações foram inseridas. Pequenos equipamentos, como bancos, o restauro da Fonte Velha, a construção de um pequeno mirante, finalizando o percurso e a revalorização de uma plataforma natural que foi integrada no caminho e albergou bancos, mesas, assadouros e um ponto de água (fig. 8). O caminho foi também iluminado.

12. MESTRE \& ALEIXO. Op. cit., 2000.

13. Idem, p. 7.

14. Cf. MESTRE; ALEIXO; PÉ-CURTO. Op. cit., 2000.
Esses fatores, novamente introduzidos com o restauro, contribuíram para a urbanização do Caminho da Fonte Velha e ajudaram a alterar seu estatuto anterior de ruralidade, fazendo-o passar a uma nova situação, que já pode ser inscrita no domínio do urbano. Em todas as intervenções - esculturas e equipamentos - foi utilizado granito da região ou similar, de 


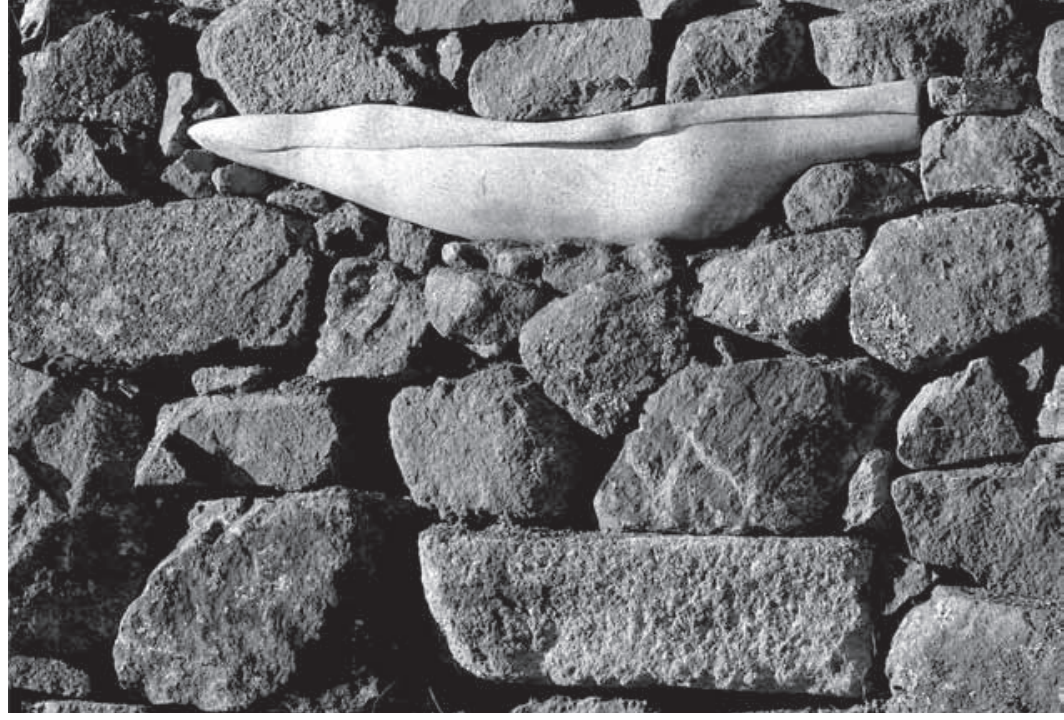

modo a sublinhar a ideia de discrição inerente aos objetivos deste projeto.

Abordando especificamente a intervenção escultórica, temos que realçar sua forte carga conceitual e assumi-la com o caráter de uma grande instalação, pois seu desenvolvimento será determinado pelas particularidades do caminho. Através de cerca de trinta elementos escultóricos, surgindo em afloramentos da rocha existentes, em pedras incorporadas nos muros ou realizadas em estaleiro e ali colocadas ${ }^{15}$, quatro escultores ${ }^{16}$ criaram trabalhos em várias tecnologias relacionadas com a tradição da escultura em pedra, como o relevo, a escultura adoçada e o vulto perfeito, modelados ou esgrafitado, ou ainda em pequenos conjuntos de objetos (constituindo também per se pequenas instalações). Colocou-se então uma tecnologia e uma disciplina a serviço de uma concepção contemporânea de escultura: a instalação.

A escultura em pedra possibilitou a utilização contemporânea de meios conotados com atuações plásticas em desuso, vindo a demonstrar que, muitas das vezes, é falsa a questão de que determinados meios de expressão estão fora de moda. A tecnologia deve ser aquela que melhor responda aos objetivos do trabalho e, neste caso, é claramente demonstrado que a conjugação de fórmulas de atuação plásticas tradicionais são perfeitamente conjugáveis com processos conceituais contemporâneos, potenciando-os.

Desse modo, todo o espaço que define o Caminho da Fonte Velha foi o suporte de intervenção dos cerca de trinta elementos escultóricos referidos que, em sua diversidade e por si só, não chegavam a ascender ao estatuto de objeto. Como outrora, a escultura inserida na arquitetura só vivia quando inserida no suporte arquitetônico. Esses elementos escultóricos, só vivem quando inseridos num suporte que, no caso deste
164

\section{Susana Piteira}

Leonardo Charréu

Campos expandidos da escultura na recuperação paisagística e urbana: um exemplo de arte pública e práticas colaborativas
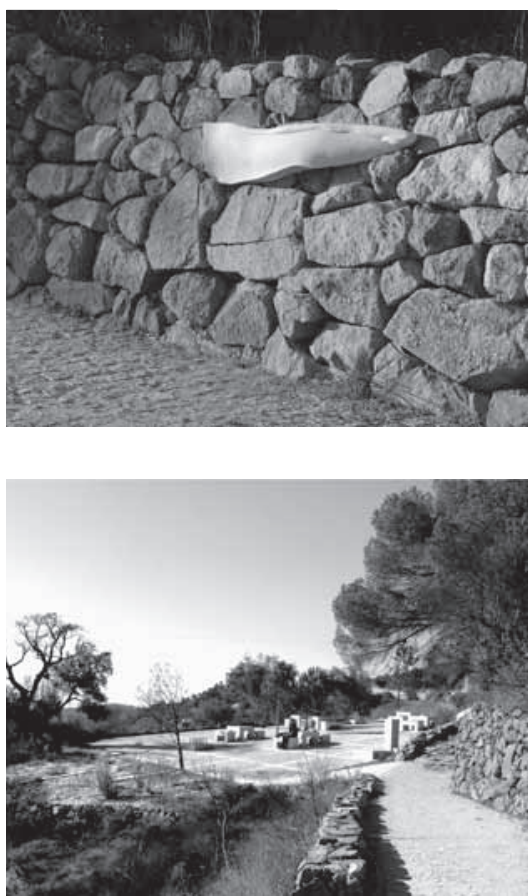

Figura 6 e 7:

Intervenção no muro medieval de trecho do Caminho da Fonte Velha. Esculturas de parede (Susana Piteira)

Figura 8:

Zona de lazer do Caminho da Fonte Velha com equipamento urbano (bancos, mesas, assadouros, bebedouros...) (Créditos fotográficos: Mário Reis/ Susana Piteira)

15. Idem, p. 4.

16. Os escultores convidados a participar foram Jorge PéCurto, que coordenou o projeto escultórico e, por sua vez, convidou Rui Matos, Susana Piteira e Victor Ribeiro. 
ARS projeto, são os muros e é também o próprio espaço. Mas o que aqui se ano 13 ambicionou foi chegar mais além. Ao partir do conceito de espacialidade,

n. 26 também sentimos que já não estamos perante a escultura simplesmente inserida na arquitetura. Aqui, afastamo-nos do conceito de colaboração e da dependência de uma arte em relação a outra e superamos as categorias pré-estabelecidas das disciplinas como propõe Javier Maderuelo ${ }^{17}$.

Entramos então na discussão sobre o peso que cada termo do binômio forma-função tem na arquitetura, o que por consequência põe em evidência a importância que tem vindo a adquirir cada um desses termos e seu caráter específico ${ }^{18}$. Avaliando, neste caso, a interferência entre escultura e arquitetura e tentando diferenciar suas essências e naturezas para averiguar até que ponto esta obra pode ser considerada escultórica ou arquitetônica, deparamo-nos com o fato da "funcionalidade como valor se encontrar associada com a arquitetura, enquanto que a qualidade formal se identifica com a plasticidade da escultura"19.

Lembramos por isso o trabalho espacial de Constantin Brancusi em Târgu-Jiu como referência, considerada como um ponto de

Figura 9 e 10:

Esculturas em alto-relevo de Jorge Pé-Curto, no muro medieval (Créditos fotográficos: Mário Reis/ Susana Piteira).

17. MADERUELO, Javier. Op. cit., 1990.

18. Idem.

19. Idem, p. 31.

20. Idem.

21. Idem, p. 39 partida das interferências da escultura no terreno da arquitetura ${ }^{20}$. Tendo naturalmente em conta os mais de sessenta anos que separam Târgu-Jiu (1938) do Caminho da Fonte Velha (2004), podemos, mesmo assim, estabelecer várias relações entre ambos. São percursos que se desenvolvem ao longo de rios, pontuados por elementos escultóricos, ultrapassam os limites tradicionais da escultura e do monumento, estendendo-se pelo território, estabelecem laços com os respectivos tecidos urbanos alcançando uma dimensão urbana que se estende até a distância de cerca de um kilômetro ${ }^{21}$.

O Caminho da Fonte Velha e Târgu-Jiu são dois processos de
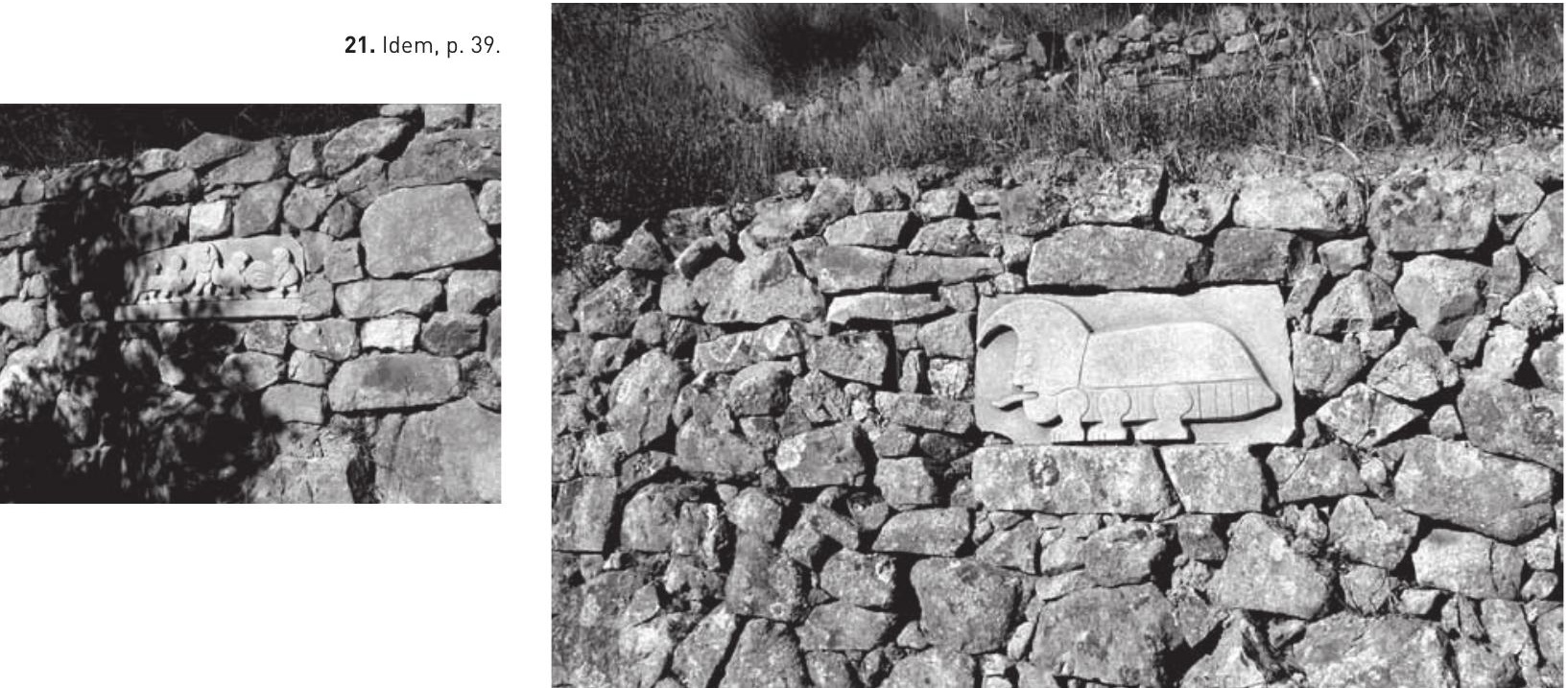
obras de arte pública, distintos entre $\mathrm{si}^{22}$, no entanto ambos negam a tradicional fórmula do monumento de escultura que, através da instauração de uma ordem vertical, dominava seu lugar de implantação. Circunscrevem-se no modo pós-moderno de encarar a colocação do monumento dentro da entropia, o antimonumento, ou dentro daquilo que Robert Smithson havia ironicamente comemorado sob o nome de "Monuments de Passaic"23. Para melhor entender esta circunstância, transcrevemos o fragmento de texto no qual a autora desenvolve essa ideia.

A forma veste-se por debaixo da matéria e a organiza de maneira discursiva, a ordem lançando uma espécie de iluminação estética sobre o que dantes poderia parecer inintelígivel. Sempre, dentro de todo o movimento do "non-site" ou "earthwork", esta tendência vertical se converteu em uma horizontalidade afirmativa onde são aceitas e aprofundadas as condições do labirinto. São admitidas as tendências à entropia e à deliquescência... e reconhecidas como irrepresentáveis. A força anárquica desta intervenção faz saltar os antigos limites da ordem estética modernista. A partir deste momento, um momento impossível de recuperar dentro dos limites da prática modernista e anunciando, segundo certos críticos, o aparecimento do pós-modernismo, novas condições fazem simultaneamente a sua aparição. Assim, a escultura pode aceder a vastas proporções, não por englobar um lugar, mas antes pela maneira como toma consciência do desafio que ele coloca à forma. Pode também fazer que os próprios limites da expressão plástica se fundam ao mesmo tempo com o "non-site" inaugurando uma prática que já não saberemos designar adequadamente com termo "escultura"24.

Em sua tipologia e dimensão, é nesse desenvolvimento de horizontalidade que os elementos escultóricos, de um e de outro caso, se distinguem. Embora venham a convergir na tarefa de definir o percurso, na relação que estabelecem entre si o conjunto ou a totalidade da obra, o fragmento específico e o todo ideal concebem um conjunto no qual as partes não serão verdadeiramente ligadas senão no nível puramente mental do plano da obra, o qual pode ser inacessível à percepção ${ }^{25}$.

Utilizei dantes a noção de domínio alargado para descrever esta explosão dos meios de expressão da escultura. Doravante tudo pode ser utilizado com vista a exprimir o caráter ilimitado do real: a arquitetura, o desenho, a fotografia, a ação política, o filme. E confundir essa atividade com a lógica do
166

Susana Piteira

Leonardo Charréu

Campos expandidos da escultura na recuperação paisagística e urbana: um exemplo de arte pública e práticas colaborativas

Figura 11 e 12:

Escultura-goteira. Susana Piteira) (Créditos fotográficos: Mário Reis/ Susana Piteira).

Figuras 13:

Escultura-goteira, detalhe. Susana Piteira) (Créditos fotográficos: Mário Reis/ Susana Piteiral.

Figura 14:

Escultura-instalação em Târgu-Jiu (Roménia) de Constantin Brancusi, 1938
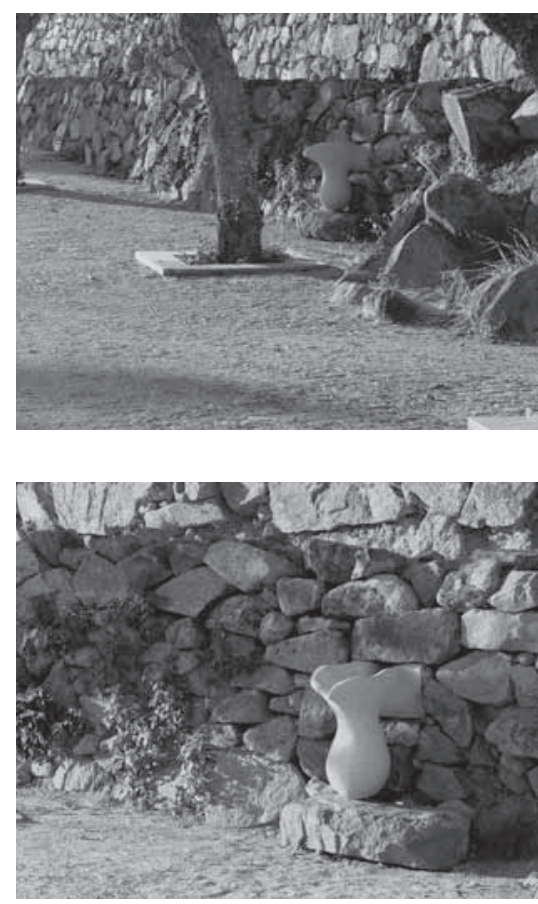


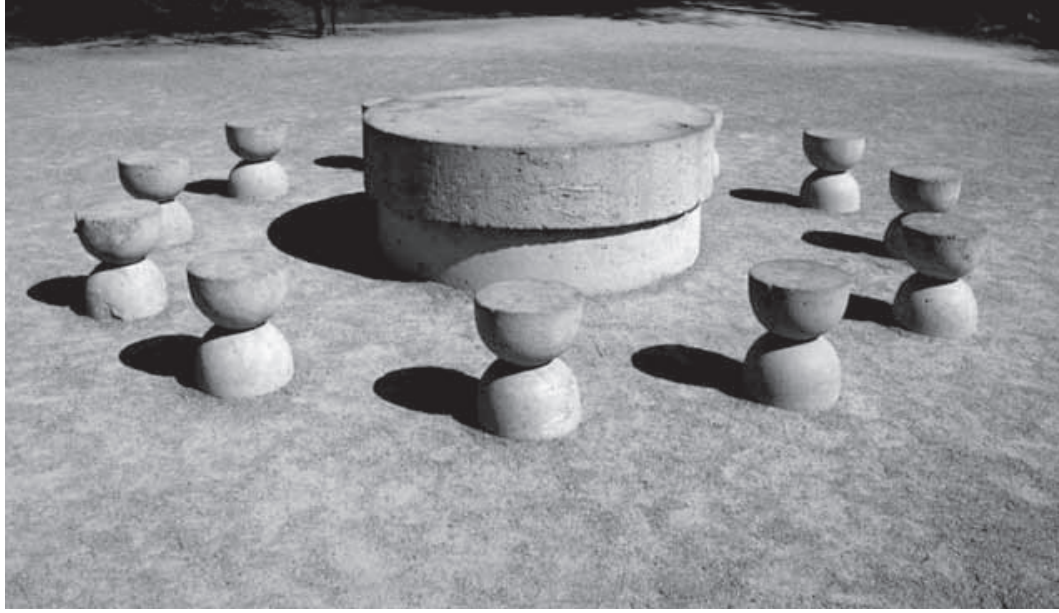

ções proporcionadas pelos cinco sentidos. Para essas sensações contribuem os elementos da natureza, os cheiros, os sons, assim como os elementos construídos, os muros, a fonte ou as intervenções dos trabalhos escultóricos. $\mathrm{O}$ apelo ao olfato ou ao tato, ao sentido auditivo ou ao visual, convidam a uma pausa na nossa acelerada vida contemporânea.

Atinge-se assim uma dimensão poética, fortemente ligada ao belo ou pitoresco. Se quisermos entender a dimensão cênica que o lugar possui, o pitoresco apresenta-se neste contexto quase na totalidade de suas possibilidades. Consumando-se, por exemplo, através da ruína da pequena casa que se encontra perto da Fonte Velha (fig. 16 e 17), do ruído da água a cantar na bica da fonte ou de alguém a trabalhar no campo. Ou ainda nos efeitos de luz e sombra que quase podem ser abordados como o faziam os pintores sensualistas italianos, Giorgione e Tiziano por exemplo, em cujos quadros o fundo paisagístico se presta a alterações luminosas e a fenômenos ambientais. Mas afastando-nos do pitoresco que designa o pictórico, no sentido gráfico (representativo) no século XVII, o pitoresco ganha autonomia e, no contexto deste projeto, assume-se também, para além de qualitativo estético, como qualitativo filosófico, comportamental e poético ${ }^{32}$.

Esses são valores aos quais a indústria do turismo não é indiferente hoje em dia ${ }^{33}$. O mito romântico da natureza foi substituído pelo mito modernista da máquina. Incapazes de viver a natureza incorporada no nosso dia a dia, devido ao atual sistema socioterritorial em que vivemos, buscamos sua ideia e consumimos seu simulacro. Esperamos que o Caminho da Fonte Velha não se torne, por isso, em mais um produto meramente turístico e nessa sequência se transforme, também ele, em seu simulacro. A necessidade de fazer algo que conserve o patrimônio, seja ele qual for - natural ou construído, alterará para sempre o seu estatuto, ainda que se reclamem as suas intervenções de reabili-
168

Susana Piteira

Leonardo Charréu

Campos expandidos da escultura na recuperação paisagística e urbana: um exemplo de arte pública e práticas colaborativas

Figura 15:

"A mesa do silêncio" escultura-instalação em Târgu-Jiu (Romênia) de Constantin Brancusi, 1938. Homenagem aos heróis romenos mortos na Primeira Guerra Mundial

23. KRAUSS, Rosalind. Échelle/monumentalité. Modernisme postmodernisme. In: CENTRE GEORGES POMPIDOU, Qu'est-ce que la sculpture moderne? Paris: Centre Georges Pompidou, 1986, p. 249.

24. Idem, ibidem.

25. Idem, p. 250.

26. Idem, p. 252-253.

27. MESTRE; ALEIXO; PÉCURTO. Op. cit., 2000, p. 4.

28. MADERUELO, Javier (ed.). William Gilpin. 3 ensayos sobre la belleza pintoresca. Madrid: Abada Editores, 2004, p. 73.

29. Poucas obras em Portugal refletem essa atitude.

Fundamentadas noutros pressupostos, por vezes, algumas obras de arte pública em Portugal, cumprem o objetivo de ser comunicativas e funcionais. Lembramos, por exemplo, "Kanimambo", de autoria de Ângela Ferreira, que fez parte do conjunto de encomendas para o Parque Expo, em Lisboa, ou o trabalho de Fernanda Fragateiro "Eu Espero", na Cidade de Santo 
Tirso lobra que integra - MIEC - Museu Internacional de Escultura Comtemporânea).

30. MADERUELO, Javier. Op. cit., 1994, p. 73

31. MESTRE; ALEIXO; PÉCURTO. Op. cit., 2000, p. 4.

32. MADERUELO, Javier. Op. cit., 2004.

33. Não deixa de ser curioso que o pitoresco, qualitativo que era sinônimo de uma particularidade cromática própria dos pintores venezianos, se difundiu através dos turistas que introduziram o termo nos seus respectivos idiomas.

Por outras razões e de forma distinta já a palavra estava associada ao turismo.

34. Ver TELLES, Gonçalo Ribeiro. Pesquisa de doutorado Arte, natureza e cidade em Portugal: uma tentativa de programação de arte pública. Lisboa, 23 jul. 2004. Entrevista concedida a Susana Piteira.

35. Cf. NEVES, José Manuel. Victor Mestre / Sofia Aleixo. Reabilitação do Tempo. Casal de Cambra: Caleidoscópio, 2004. ser simbólico em relação às memórias que contém (em particular para os habitantes do lugar), mas adquiriu a dimensão do lazer, o que lhe retira o caráter outrora exclusivamente rural. Ao abandonar a sua primeira função, adquiriu assim a dimensão do cultural que, como Ribeiro Telles define ${ }^{34}$, é a simbiose do rural com urbano. Nesse sentido, esta intervenção poderá ser considerada um fragmento no ordenamento de paisagem nacional e um prenúncio de alguma mudança, em escala micro, de atitude face ao ordenamento do território.

Num processo liderado pela disciplina da arquitetura, os arquitetos desempenharam o papel de mediadores, articulando as diferentes dimensões do projeto. Atuaram como se fosse necessário anular o desenho, pois o lugar já estava lá e só era necessário consolidá-lo ${ }^{35}$. A partir do concurso público, lidaram com questões jurídicas e lançaram a lógica projetual. Para ser desenvolvida, esta lógica necessitou de uma equipe diversificada ao nível das disciplinas e obrigou que este trabalho fosse desenvolvido desde o primeiro momento com essa mesma equipe; sendo a escultura, como já se aludiu, a principal marca da intervenção. O escultor participou naquilo que podemos considerar a estrutura do projeto, contribuindo para sua definição. Essa postura terá sido definidora do caráter que vieram a assumir as intervenções escultóricas. Sua função estrutural neste projeto as afastou de cair na dimensão decorativa, pois fazem parte integrante do espaço em vez de lhe terem sido somadas posteriormente. Devido à escala da intervenção, foi considerado benéfico convidar mais três escultores para além do coordenador escultor Jorge Pé-Curto, com o fim de diversificar as características dos chamados sinais.

À alteração do modus operandi artístico, provocada primeiro pela intervenção em Târgu-Jiu, de Brancusi, seguido pela prática da longa carreira de Noguchi e mais recentemente pela incontornável atitude e obras de Siah Armajani, podemos cruzar o movimento dos earthwork. Este cruzamento de atitudes marcará profundamente toda arte contemporânea e vem obrigar a uma redefinição de temas tão importantes como a autoria, o estatuto de autonomia das artes e o objeto de arte estático e portátil, o mercado da arte e o papel das instituições que tradicionalmente se ocupam de sua divulgação, o papel da encomenda, do artista como mediador ou, ainda, as questões da interdisciplinariedade, sobretudo aquelas associadas à arte pública no contexto urbano. Nessa abordagem, 
não poderemos negligenciar o público e sua forma de relacionamento com as atuações artísticas. Por essa razão, voltamos a Siah Armajani desejando aderir a sua posição relativa à relação das pessoas com o trabalho artístico desenvolvido no espaço público. Assim, em 1986 o escultor definiu o conteúdo e o sentido do termo arte pública com estas palavras:

A nossa intenção é a de voltar a ser cidadãos. Não estamos interessados no mito criado em torno dos artistas e para os artistas. O que nos importa é a missão, o programa e a obra em si. Por meio de atuações concretas, em situações concretas, a arte pública adquiriu um certo caráter. Uma das crenças fundamentais que partilhamos é a de que a arte pública é não monumental. É humilde, comum e próxima das pessoas. É uma anomalia numa democracia celebrar com monumentos. Uma democracia verdadeira não deve procurar "heróis" já que exige que cada cidadão participe plenamente na vida quotidiana e que contribua para o bem público. (...) preconizamos a unidade da aproximação coletiva ao programa comum em lugar da aproximação individual porque sentimos que a ideia de individualidade é bárbara e que a obra de colaboração é a metodologia essencial para identificar e resolver os problemas públicos ${ }^{36}$.

Desta forma, acreditamos ter sido ensaiada em Portugal com o Caminho da Fonte Velha uma conduta profissional e ética pouco comum, esboçando o processo necessário ao desenvolvimento desse tipo de projetos, que assume não apenas uma dimensão espacial como também uma dimensão conceitual de fronteira, ou melhor, de permeabilização entre disciplinas. Essa perspectiva de trabalho implica, por vezes, uma vasta gama de profissões, convergindo para a sua formulação e execução. Requer, por isso, uma prática colaborativa constante. Numa lógica que pensamos já ser pós-modernista, estruturando-se sempre entre os limites da arquitetura e da escultura, o trabalho atinge, é certo, uma grande escala, desenvolvendo-se através da horizontalidade do percurso, o que as imagens que escolhemos para o ilustrar podem não dar conta. Sabemos sim que este projeto ultrapassa as formas tradicionais da escultura, tomando como base o pensamento estético de Javier Madaruelo, Rosalind Krauss e Siah Armajani, para se constituir, ele próprio, numa representação que julgamos coerente com as premissas prévias locais que serviram de guião ao projeto. Consequentemente, ele afirma-se por sua impossibilidade de aterritorialidade, na medida em que o fragmento de território que assim foi recuperado e reabilitado conseguiu manter um certo espírito rural

\section{Susana Piteira}

Leonardo Charréu

Campos expandidos da

escultura na recuperação

paisagística e urbana: um exemplo de arte pública e práticas colaborativas
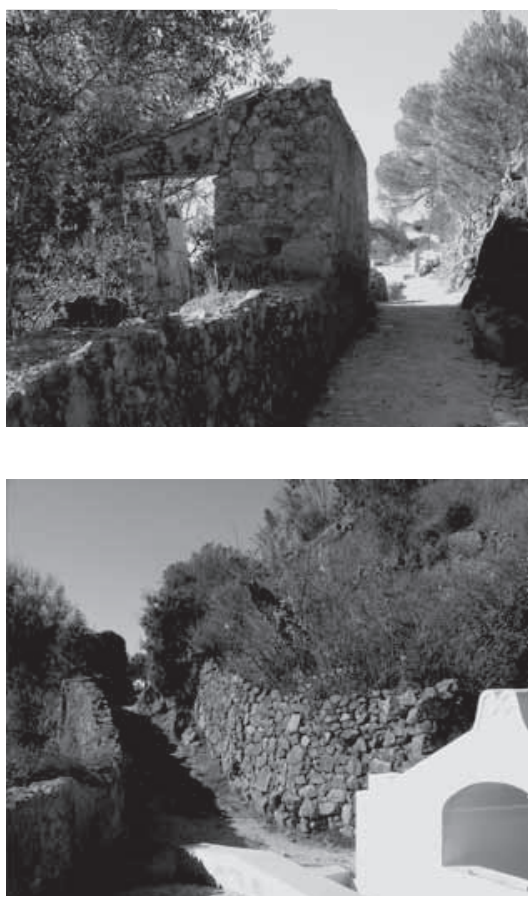

Figuras 16 e 17:

Pormenor da casa em ruínas (16) e a Fonte Velha recuperada (17) (Créditos fotográficos Mário Reis/ Susana Piteira).

36. SIAH ARMAJANI apud MADERUELO, Javier.

Op. cit., 2004, p. 74.

Figura 18:

Final do caminho. Pormenor do belvedere, com escultura zoomórfica de alto-relevo de Susana Piteira. 
ARS do lugar, que já possuía no passado, harmonizado agora com uma nova ano 13 condição que podemos considerar urbana. Ousamos convidar o leitor a

n. 26 visitá-lo, conscientes que a experiência do nosso corpo, no lugar, ou melhor no percurso (porque o caminhar fará parte da experiência estética a experimentar neste lugar) poderá acrescentar aquilo que as palavras, por mais elaboradas e poéticas que sejam... não podem expressar.

Figura 19:

Vista da Fonte Velha lcom pormenor), alto-relevo escultórico de Jorge Pé-Curto.

(Créditos fotográficos: Mário Reis e Susana Piteiral

Artigo recebido em 23 de Julho de 2015 e aprovado em 10 de Agosto de 2015.
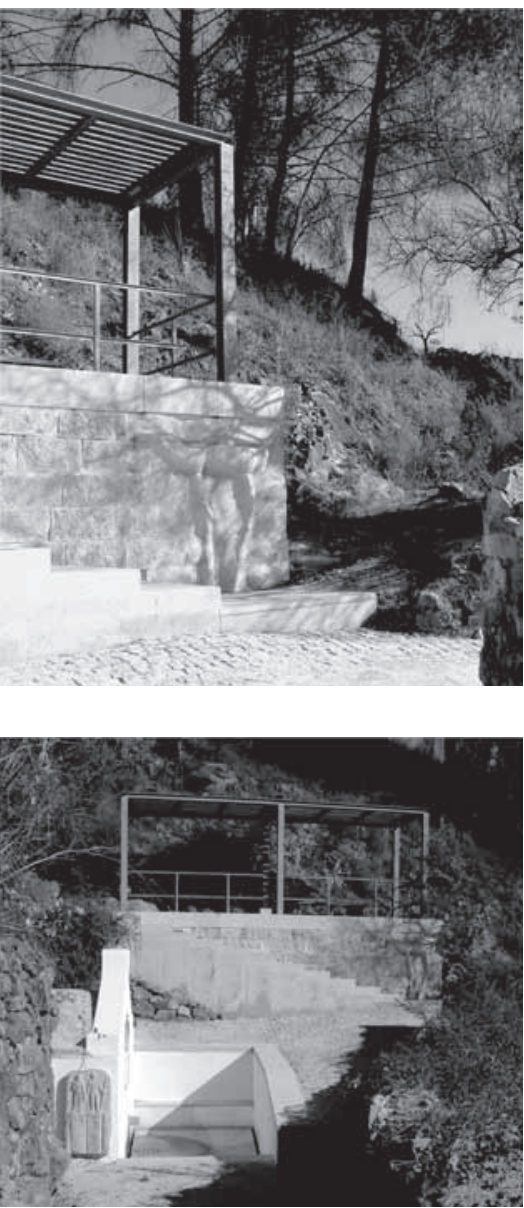

\section{Bibliografia complementar}

MUSEU D 'ART CONTEMPORANI DE BARCELONA. Siah Armajani. Espacios de lectura/Reading Spaces. Barcelona: MACBA, 1995.

BEARDSLEY, John. Earthworks and beyond. New York: Abbeville Press, 1998. CASEY, Edward S. Earth-mapping, artists reshaping landscape. Minneapolis: University of Minnesota Press, 2005.

FLAM, Jack. Robert Smithson: The collected writings. Berkeley: University of California Press, 1996.

PÉ-CURTO, Jorge. Pesquisa de doutorado Arte, natureza e cidade em Portugal: uma tentativa de programação de arte pública. Lisboa, 7 jul. 2004. Entrevista concedida à Susana Piteira.

Agradecimentos: Gonçalo Ribeiro Telles; Jorge Pé-Curto; José Guilherme de Abreu; Mário Reis; Juliana Salbego, Marilda Oliveira, Victor Mestre e Sofia Aleixo.

Susana Piteira é licenciada em Escultura pela Faculdade de Belas Artes da Universidade do Porto. Possui o certificado de suficiência investigadora pela Faculdade de Belas Artes de Barcelona, Espanha, onde está finalizando seu doutorado. É professora auxiliar convidada de Escultura na Faculdade de Belas Artes da Universidade do Porto. Integra o CIEBA (Centro de Investigação em Belas Artes da Faculdade de Belas Artes da Universidade de Lisboa).

Leonardo Charréu é licenciado em Pintura pela Faculdade de Belas Artes da Universidade do Porto. É mestre em História da Arte pela Universidade Nova de Lisboa e doutor em Belas Artes pela Universidade de Barcelona. É investigador colaborador no I2ADS (Instituto de investigação em Arte, Design Sociedades da Universidade do Porto) e do GEAPEC (Grupo de Estudos em Arte, Educação e Cultura) da Universidade Federal de Santa Maria onde é vice-líder e coordena o NEPIC (Núcleo de Estudos e Pesquisas em Ilustração Científica). É coeditor da Revista Digital do Laboratório de Artes Visuais. 